\title{
Flight safety in patients with arrhythmia
}

\author{
Fahrettin Katkat (D)
}

Department of Cardiology, Health Sciences University, Bağclar Training and Research Hospital; İstanbul-Turkey

\section{ABSTRACT}

As it is comfortable, fast, and safe, an increasing number of patients with heart disease prefer to travel by flight. However, there is not much information about the problems that patients with arrhythmia may experience during air travel. In addition, the precautions to be taken with these patients during a flight are uncertain. In this review, the management of patients with cardiac conduction problems during flight was examined in detail.

Keywords: air travel, cardiovascular disease, arrhythmia

\section{Introduction}

Nowadays, as it is safe, fast, and comfortable, more people prefer air travel; however, this is a stressful environment for the human body. According to the rules of the Federal Aviation Administration, the cabin pressure of a commercial aircraft should be kept below 8,000 feet (1), which corresponds to an altitude of $2,438 \mathrm{~m}$ and is considered the upper limit. The pressure at the height of $6,000-8,000$ feet corresponds to approximately 0.16 of the oxygen fraction $\left(\mathrm{FiO}_{2}\right)$ inhaled at sea level $(2$, $3)$. In addition, air at higher pressures contains lower humidity (4). These factors can worsen the condition of patients with arrhythmia.

The catecholamine level may increase owing to flight stress. In addition, some studies have shown that catecholamine levels increase during flight because of acute hypoxia (5). Increased sympathetic activation owing to acute hypoxia and increased catecholamine levels may increase the risk of cardiac arrhythmias (6). However, the incidence of significant arrhythmias during air travel is very rare. In a study of healthy male volunteers between the ages of 50 and 64, an increase in atrial and ventricular ectopic beats was reported with a sudden rise up to $2,632 \mathrm{~m}$ above sea level in a cable car. In addition, the frequency of ectopia has been proposed to be proportional to altitude. However, these findings were not found to be associated with an increase in sustained ventricular arrhythmia (7). In another study with healthy volunteers in a room that simulated the height of Mount Everest, researchers found that in proportion to the degree of hypoxia, heart rate increased, and temporal changes in the mean frontal QRS axis and voltage occurred (8). However, besides these findings, they observed that arrhythmic changes did not occur in electrocardiography (ECG) even in an environment where the oxygen saturation was $49 \%$.

Air travel itself does not cause paroxysmal supraventricular tachycardia, atrial fibrillation, or atrial flutter. Patients who are asymptomatic or symptomatically stable should not be restricted from flying.

Patients with permanent or persistent atrial fibrillation can fly after adequate rate control and anticoagulation. Patients with a history of ventricular arrhythmia are advised to consult their doctor before air travel. However, those with uncontrolled ventricular or supraventricular arrhythmias should not be allowed to fly (9). As there is a small additional risk of thromboembolism during or after a flight, any passenger wishing to fly within 1 week of left or right-sided ablation therapy for arrhythmia should be considered as high risk for deep venous thrombosis/venous thromboembolism (10). As is known, implantation of cardiac electronic devices may be complicated by pneumothorax after subclavian vein puncture. It is generally followed conservatively, and rarely is any intervention required $(0.6 \%-0.8 \%)$. Patients with pneumothorax have a risk of developing respiratory distress and tension pneumothorax because of the risk of gas expansion with altitude during a flight. Therefore, in a patient with pneumothorax complicating device implantation, the flight should be delayed for up to 2 weeks after full radiological resolution, regardless of whether intervention is required. If the cardiac device insertion has been uncomplicated, there is no absolute contraindication for the patient to fly 1-2 days follow- 
ing the procedure; however, a small increased risk of pneumothorax has been reported. In addition, as small pneumothoraxes may sometimes not be noticeable on chest radiographs, delaying flight for a while may provide time for spontaneous resolution. Patients should also be advised to restrict arm movements on the side of placing the device, avoid raising the elbow over the shoulder, and avoid heavy lifting to minimize the risk of lead displacement (10).

Patients with implantable heart defibrillators (ICD) are at the greatest risk for development of sustained ventricular arrhythmia during air travel. However, no case series with an increase in ICD shock incidence during the air travel of patients with ICD has been shown to date. There is also no study with an increased incidence of sustained atrial arrhythmia $(11,12)$. It is still unknown whether hypoxia during air travel is associated with increased risk of sustained ventricular arrhythmia and implantable cardioverter defibrillator (ICD) activation in susceptible individuals. It has been proposed that profound hypoxemia induced by inhalation of a gas mixture containing $10 \%$ oxygen causes a significant and reversible increase in the pacing threshold (13). However, exposing 13 patients with implanted pacemakers to a hypobaric environment equivalent to $4000 \mathrm{~m}$ altitude did not cause any change in stimulation thresholds after 30 minutes (14).

Patients with arrhythmia should be careful about intake of liquids containing alcohol and caffeine during air travel, as it can contribute to dehydration in a less humid environment and can also interact with the drugs currently used (15). Discontinuation of treatment by leaving the medications in luggage in the cargo hold, especially during long air travel, may increase the risk of arrhythmia. Patients should keep the required medication in their hand luggage during travel. It may be useful to have their latest ECG with them. Patients with pacemaker and ICD should have their device cards with them.

According to the rules of the Federal Aviation Administration, which came into force on April 12, 2004, passenger aircraft with a maximum carrying capacity of 7,500 lbs and at least one flight crew must have an automated external defibrillator (AED) and emergency medical kit. All aircraft personnel should be trained in the usage of AEDs and in cardiopulmonary resuscitation. The rule came into force on April 12, 2004. In a study of data on AED use by one major US airline, Page et al. reported that the widespread availability of AEDs on commercial airlines might save the lives of 93 persons with ventricular fibrillation each year (16). In such patients, long-term survival rates range from $26 \%$ to $40 \%$, compared with $2 \%$ to $5 \%$ long-term survival rates reported frequently for non-hospital arrests (16-18).

\section{Conclusion}

It is extremely rare for significant arrhythmias to occur during air travel, and air travel itself does not cause clinically significant arrhythmias. Patients with arrhythmia can travel by plane safely if they are asymptomatic or clinically stable.
Conflict of interest: None declared.

\section{References}

1. Gong $\mathrm{H}$ Jr. Air travel and oxygen therapy in cardiopulmonary patients. Chest 1992; 101: 1104-13. [Crossref]

2. Humphreys S, Deyermond R, Bali I, Stevenson M, Fee JP. The effect of high altitude commercial air travel on oxygen saturation. Anaesthesia 2005; 60: 458-60. [Crossref]

3. Kodama D, Yanagawa B, Chung J, Fryatt K, Ackery AD. "Is there a doctor on board?": Practical recommendations for managing inflight medical emergencies. CMAJ 2018; 190: E217-22. [Crossref]

4. Thibeault C, Evans AD. AsMA Medical Guidelines for Air Travel: stresses of flight. Aerosp Med Hum Perform 2015; 86: 486-7. [Crossref]

5. Demmons LL, Cook EW 3rd. Anxiety in adult fixed-wing air transport patients. Air Med J 1997; 16: 77-80. [Crossref]

6. Possick SE, Barry M. Evaluation and management of the cardiovascular patient embarking on air travel. Ann Intern Med 2004; 141: 148-54. [Crossref]

7. Kujaník S, Snincák M, Galajdová K, Racková K. Cardiovascular changes during sudden ascent in a cable cabin to the moderate altitude. Physiol Res 2000; 49: 729-31.

8. Malconian M, Rock P, Hultgren H, Donner H, Cymerman A, Groves $B$, et al. The electrocardiogram at rest and exercise during a simulated ascent of Mt. Everest (Operation Everest II). Am J Cardiol 1990; 65: 1475-80. [Crossref]

9. Roby H, Lee A, Hopkins A. Safety of travel following acute myocardial infarction. Aviat Space Environ Med 2002; 73: 91-6.

10. Smith D, Toff $W$, Joy M, Dowdall N, Johnston R, Clark L, et al. Fitness to fly for passengers with cardiovascular disease. Heart 2010; 96 Suppl 2: ii1-16. [Crossref]

11. Lampert R, Joska T, Burg MM, Batsford WP, McPherson CA, Jain D. Emotional and physical precipitants of ventricular arrhythmia. Circulation 2002; 106: 1800-5. [Crossref]

12. Fries R, König J, Schäfers HJ, Böhm M. Triggering effect of physical and mental stress on spontaneous ventricular tachyarrhythmias in patients with implantable cardioverter-defibrillators. Clin Cardiol 2002; 25: 474-8. [Crossref]

13. Westerholm CJ. Threshold studies in transvenous cardiac pacemaker treatment. Direct measurement with special reference to short and long term stimulation and influence of certain metabolic, respiratory and pharmacological factors. Scand J Thorac Cardiovasc Surg Suppl 1971; 8: 1-35.

14. Weilenmann D, Duru F, Schönbeck M, Schenk B, Zwicky P, Russi $E W$, et al. Influence of acute exposure to high altitude and hypoxemia on ventricular stimulation thresholds in pacemaker patients. Pacing Clin Electrophysiol 2000; 23: 512-5. [Crossref]

15. Shepherd B, Macpherson D, Edwards CM. In-flight emergencies: playing The Good Samaritan. J R Soc Med 2006; 99: 628-31. [Crossref]

16. Page RL, Joglar JA, Kowal RC, Zagrodzky JD, Nelson LL, Ramaswamy $\mathrm{K}$, et al. Use of automated external defibrillators by a U.S. airline. N Engl J Med 2000; 343: 1210-6. [Crossref]

17. O'Rourke MF, Donaldson E, Geddes JS. An Airline Cardiac Arrest Program. Circulation 1997; 96: 2849-53. [Crossref]

18. Robertson RM. Sudden death from cardiac arrest-improving the odds. N Engl J Med 2000; 343: 1259-60. [Crossref] 